\section{Cahiers de littérature orale}

75-76 | 2014

L'autre voix de la littérature

\title{
Récits marquisiens. Récits traditionnels des îles Marquises
}

Traduction de Henri Lavondès, Coordination et présentation de JeanMarie Privat, Notes et glossaire de Marie-Noëlle Ottino-Garanger, Grenoble, Ellug, Université Stendhal, 2013, 218 p.

Sophie Chave-Dartoen

\section{Q OpenEdition}

1 Journals

Édition électronique

URL : https://journals.openedition.org/clo/2131

DOI : $10.4000 /$ clo. 2131

ISSN : 2266-1816

Éditeur

INALCO

Édition imprimée

Date de publication : 1 janvier 2014

ISBN : 978-2-85831-222-1

ISSN : 0396-891X

Référence électronique

Sophie Chave-Dartoen, «Récits marquisiens. Récits traditionnels des îles Marquises », Cahiers de littérature orale [En ligne], 75-76 | 2014, mis en ligne le 13 mai 2015, consulté le 01 juillet 2021. URL : http://journals.openedition.org/clo/2131 ; DOl : https://doi.org/10.4000/clo.2131

Ce document a été généré automatiquement le 1 juillet 2021.

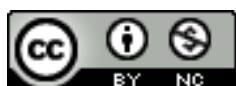

Cahiers de littérature orale est mis à disposition selon les termes de la Licence Creative Commons Attribution - Pas d'Utilisation Commerciale 4.0 International. 


\section{Récits marquisiens. Récits traditionnels des îles Marquises}

Traduction de Henri Lavondès, Coordination et présentation de JeanMarie Privat, Notes et glossaire de Marie-Noëlle Ottino-Garanger, Grenoble, Ellug, Université Stendhal, 2013, 218 p.

\section{Sophie Chave-Dartoen}

1 Il est des textes dont les seules qualités littéraires et poétiques suffiraient à les classer dans un trésor universel. C'est certainement le cas des Récits marquisiens, traduits par Henri Lavondès et qui ont été récemment réédités sous la forme d'un petit volume préfacé par Jean-Marie Privat.

2 Le texte introductif à ces onze courts récits insiste sur leur qualité et sur celle de la traduction. Il nous permet aussi de saisir leur destin, celui de leurs conteurs et de la société marquisienne, profondément bouleversée, lors de la collecte, après deux siècles de contacts dévastateurs avec le monde occidental. Claude Lévi-Strauss a mis en miroir nos propres coutumes et de tels corpus mythiques qui nous en présentent « une image énigmatique [...] qui demande à être décryptée » $(1962,251)$. Jean-Marie Privat cite ce dernier, quand il affirme que «nul besoin donc d'être un 'sauvage' pour se risquer à cette traversée des signes» (Privat, 2013, 18). Il nous invite à «l'accueil d'une esthétique et d'une éthique de l'oralité ancienne et insulaire » (Privat, 2013, 18). Chaque texte est rapidement présenté, et des relations tissées entre des thématiques panculturelles.

3 On ne peut, en effet, rester insensible à la beauté et à l'étrangeté de ces récits: "étrangeté» qui demande à être déchiffrée, au-delà même de la traduction de H. Lavondès. Quelques éléments de contextualisation sont proposés au lecteur : certains termes vernaculaires qui font «sens à la fois d'un point de vue anthropologique et culturel » ont été réintroduits, assortis d'un lexique qui donne également la traduction de certains noms propres. Des annotations d'H. Lavondès (trop rares, peut-être) ont également été ajoutées pour éclairer certains passages obscurs.

4 Si ces récits sont fascinants et, d'une certaine façon, existent en eux-mêmes, une approche compréhensive ouvre aux formes de pensée et aux pratiques linguistiques, 
essentiellement orales, dont ils témoignent. Cette lecture ne peut ainsi que nous conduire vers les analyses qu'en fit H.Lavondès dans une thèse d'État (1975) malheureusement difficile à trouver. Elle ouvre aussi à la comparaison régionale en ce que ces textes parlent d'une société polynésienne, mais parlent également du monde polynésien et de son univers de pratiques et de pensée.

Le premier des récits est exemplaire à cet égard : l'Histoire de Ati Papa présente ainsi des caractéristiques formelles et thématiques attestées à Samoa ou à Wallis, archipels situés plusieurs centaines de kilomètres plus à l'ouest. La prosodie, tout d'abord, avec l'insertion récurrente d'échanges dialogués qui reposent sur le jeu d'interrogations et d'exclamations généralement très marquées dans l'énonciation. Un double jeu de scansions anime donc certaines parties du texte, par l'insertion des échanges, mais aussi dans l'organisation même de ces échanges. Avec le rang respectif des protagonistes, implicite mais net, la dimension performative de leurs énoncés est manifeste pour un auditoire local (exemple pris p. 36, mais répété sous des formes comparables à plusieurs reprises dans le récit du voyage) :

TEHITUTAIMOANA : 1 - qu'avez-vous vu cette nuit?

Les gens d'âge mûr : 2 - la terre est proche de nous, dirent-ils.

TEHITUTAIMOANA : 3 - vraiment?

Les gens d'âge mûr : 4 - oui, dirent-ils.

1. Le protagoniste de haut statut amorce l'échange,

2. Une réponse lui est faite.

3. L'interrogation qui reçoit cette réponse ne marque pas le doute. Du haut de son autorité, Tehitutaimoana prend acte de cet énoncé et lui donne une conséquence dans le champ social. Il s'agit là d'une forme de reconnaissance, d'un acte de parole qui, généralement, débouche sur une décision et/ou une action (Duranti, 1988, 1993).

4. Cet acte de parole est lui-même scellé par les interlocuteurs qui le renforcent d'une affirmation.

D'autres séquences de forme répétitive reposent sur ce principe - pan-régional - de la performativité particulière des paroles du chef dont l'action est, avant tout, parole, et dont la parole organise et valide paroles et actions des subordonnés :

Tehitutaimoana dit aux gens d'âge mûr :

- Réveillez-vous et allez voir cette chose qui se trouve devant nous.

Les hommes d'âge mûr se réveillèrent et allèrent regarder. (p. 38)

Ou encore :

Tehitutaimoana dit :

- Rangez-les soigneusement.

Ils rangèrent ces plumes. (p. 42).

Si l'ordre et la forme des échanges donnent à saisir le statut et l'autorité respectifs des protagonistes, leur répétition l'affirme et reconduit dans la structure même du récit celle de la société locale. Elle y imprime également la marque des théories locales de l'action, qui doit être mise en mots - et prononcée d'une position d'autorité - pour prendre consistance, exister.

9 La répétition de certaines séquences de l'action répond, par ailleurs, à des principes plus proprement sémantiques: la répétition d'un lexème, par exemple, diminue généralement la portée de l'action qu'il désigne, la répétition d'une séquence descriptive, en revanche, indique l'insistance ou la durée: "L'esprit nagea dans le courant. Il nageait, il nageait. L'esprit épuisa ses forces à nager contre le courant... » (p. 45) 
10 De telles répétitions travaillent la forme du texte, lui donnant, de loin en loin, un rythme que l'expression orale souligne et renforce. Toutefois, l'essentiel ici n'est pas le rendu formel, affaire de style, mais la question de sens : la répétition de séquences plus ou moins longues et détaillées (chargement des pirogues, alternance du jour et de la nuit durant le voyage, fabrication du piège...) plonge l'auditeur au cœur de l'action, mobilisant son expérience pour saisir, au-delà de l'action mentionnée, sa durée, sa portée, son efficacité.

11 Parmi les innombrables commentaires que suscitent ces textes magnifiques, je souhaiterais souligner un autre point qui renvoie, lui aussi, à une réalité pan-régionale, suffisamment complexe pour être souvent mal comprise. Jean-Marie Privat conclut sa courte synthèse sur le texte en indiquant, au sujet du premier récit : «La communauté a désormais un authentique chef qui a côtoyé l'invisible et le sacré» (p. 13). Certes, l'Histoire de Ati Papa prend la forme d'un mythe fondateur présentant le voyage initiatique d'un jeune homme choisi pour diriger une expédition lointaine. Mais en le conduisant au loin, elle le conduit au plus près de son ancêtre. Arrivant de l'île natale à l'invocation de son petit-fils, il tue les esprits malfaisants qui cherchaient à l'entraîner dans la mort, rétablit ainsi des conditions de navigation favorables et assure la réussite d'une expédition qui assied définitivement le statut et l'autorité de son descendant.

L'Histoire de Ati Papa nous livre ainsi les dessous d'un phénomène généralement appelé mana, que, on le voit bien ici, le terme "pouvoir " traduit approximativement. Si le rang personnel et l'autorité de Tehitutaimoana sont rehaussés par le succès de l'expédition, ce n'est pas du fait d'un mana revenant à du pouvoir (quel pouvoir auraitil pu exercer sur les esprits malfaisants et les flots déchainés ?). C'est bien plutôt du fait d'une relation étroite avec un ancêtre bienveillant qui, à son appel, met tout en œuvre pour sauver sa vie et celle des gens dont il a la responsabilité...

13 La question du mana revient dans les autres textes, mais c'est certainement dans le récit appelé 'Ikitepanoa qu'elle apparaît, encore une fois, de façon éclairante. Le protagoniste appelé $T u$ y fait preuve de capacités extraordinaires (changement d'âge, passage du monde des vivants, "terre de lumière ", à celui des morts, Havaiki...). Or, Tu est un enfant mort-né qui, plus que tout autre homme, relève aussi du monde d'où les ancêtres agissent de façon efficace au bénéfice de leurs descendants et autres dépendants. Le mythe présente ainsi la geste de $T u$ comme celle d'une figure ancestrale et tutélaire dont, fait essentiel, la vie suit le décès. Remarquons la performativité de ses lamentations répétées en séquences successives : elles obligent ses proches à aller voler à quatre reprises de la nourriture au péril de leur vie (p. 127-130), et entrainent la préparation des aliments sans que le héros ne fasse aucune des cinq étapes du travail qui lui sont demandées (p. 136-137).

the d'une theorie locale de l'action (et non de "pouvoir »): les chefs étant choisis parmi les vivants manifestant, par la réussite de leur action (invocations, lamentations..., c'est-à-dire des actes de parole, on l'aura noté), des connexions proches, efficaces, bénéfiques, avec des ancêtres. Mentionnons le motif, également relevé en Polynésie occidentale, de morts (" esprits", "fantômes »...) pouvant être tués, les êtres doublement morts étant privés d'interaction avec les vivants, ce qui n'est pas le cas des morts de haut statut que sont généralement les ancêtres.

Je n'entreprendrai pas une présentation détaillée des autres textes du recueil et de leurs multiples aspects. Tous sont d'une grande beauté et d'un grand intérêt. J'espère, en ayant suggéré ces quelques clés de lecture, avoir donné une idée de la densité du 
propos cachée à nos yeux par l'« étrangeté » de son exotisme, et éveillé une curiosité qui ramènera le lecteur vers les travaux d'analyse qu'Henri Lavondès a réalisés par ailleurs (des éléments de bibliographie sont donnés p. 25-27 du recueil).

\section{BIBLIOGRAPHIE}

DURANTI, Alessandro, 1988, Intentions, Language, and Social Action in a Samoan Context, Journal of Pragmatics, vol. 12, $\mathrm{n}^{\circ}$ 1, pp. 13-33.

DURANTI, Alessandro, 1993, Truth and Intentionality: an Ethnographic Critique, Cultural Anthropology, vol. 8, n 2, pp. 214-245.

LAVONDÈs, Henri, 1975, Terre et mer : pour une lecture de quelques noms polynésiens, Thèse pour le doctorat ès-lettres, Paris, Université René Descartes.

LÉVI-STRAUSS, Claude, 1962, la Pensée sauvage, Paris, Plon. 